\title{
Regulatory effects of apoptosis-associated speck-like protein on cytokines in the P388D1 macrophage-like cell line
}

\author{
SHUANGYI REN $^{1}$ and HAILONG CHEN ${ }^{2}$ \\ ${ }^{1}$ Department of Surgery, The Second Affiliated Hospital of Dalian Medical University, Dalian, Liaoning 116023; \\ ${ }^{2}$ Department of Surgery, The First Affiliated Hospital of Dalian Medical University, Dalian, Liaoning 116011, P.R. China
}

Received February 19, 2012; Accepted June 15, 2012

DOI: $10.3892 / \mathrm{mmr} .2012 .1124$

\begin{abstract}
Apoptosis-associated speck-like protein (ASC) is an adaptor molecule of caspase-1 activation that stimulates the secretion of multiple pro-inflammatory cytokines. We investigated the regulatory effects of ASC in the P388D1 macrophage-like cell line. Data showed that ASC overexpression induced by pEGFP-ASC-C2 transfection significantly increased caspase- 1 expression and interleukin (IL) $-1 \beta$ and IL- 6 secretion, but did not affect tumor necrosis factor (TNF)- $\alpha$ secretion. However, siRNA against ASC significantly decreased the caspase- 1 expression and IL-1 $\beta$ and IL- 6 secretion, but did not affect TNF- $\alpha$ secretion in the P388D1 cells. We suggest that ASC acts as an inflammatory responseassociated gene by regulating caspase- 1 activation and IL- $1 \beta$ and IL-6 secretion, which may correlate with its biological effects.
\end{abstract}

\section{Introduction}

Inflammation is a complex defence mechanism in which leukocytes migrate from the vasculature into damaged tissues to destroy the agents that potentially cause tissue injury. The cytokines that are produced during inflammatory processes, and are involved in them, are stimulators of the production of acute phase proteins. These inflammation-associated cytokines include interleukin (IL)-1 $\beta$, IL-6 and tumor necrosis factor (TNF)- $\alpha$ (1). They are produced by a variety of cell types, but the most important sources are macrophages at inflammatory sites. These cytokines activate macrophages to phagocytose invading pathogens and release toxic oxygen and nitrogen radicals.

Apoptosis-associated speck-like protein (ASC), containing a C-terminal caspase recruitment domain, is an adaptor

Correspondence to: Dr Hailong Chen, Department of Surgery, The First Affiliated Hospital of Dalian Medical University, 222 Zhangshan Road, Dalian, Liaoning 116011, P.R. China

E-mail: hailongchen2007@hotmail.com

Key words: apoptosis-associated speck-like protein, caspase-1, interleukin-1 $\beta$, interleukin- 6 , tumor necrosis factor- $\alpha$ molecule that mediates inflammatory and apoptotic signals and is predominantly expressed in macrophages and mucosal epithelial cells (2). It comprises two protein-protein interaction domains (PYD, an N-terminal PYRIN-domain; and CARD, a C-terminal caspase-recruitment domain) (3). The two domains are members of the 6-helix bundle death domain-fold superfamily that mediate the assembly of large signaling complexes in apoptotic and inflammatory signaling pathways. ASC is mainly known as an integral component of the inflammasome, which mediates the activation of caspase-1 (4-6). Within the inflammasome, ASC links caspase-1 and NOD-like receptors (NLR) (7-10). It has been reported that ASC functions as a critical component of the inflammasome by linking microbial and endogenous danger signals to caspase-1 activation (11).

Caspase-1 is involved in the processing and secretion of pro-inflammatory molecules and is often referred to as a pro-inflammatory caspase $(12,13)$. It is present in the cytosol of macrophage cells as an inactive zymogen $(14,15)$. Upon stimulation by multiple microbial and endogenous signals, the dormant pro-caspase-1 zymogen is self-activated by proteolytic cleavage into an enzymatically active heterodimer comprising two 10- and 20-kDa subunits (16). Activated caspase-1 is essential for the processing and release of mature IL-1 $\beta$, which is the biologically active form of IL-1 $\beta(17,18)$. Mature IL-1 $\beta$ is predominantly expressed by activated monocytes, macrophages and polymorphonuclear phagocytes. It is involved in numerous immune responses, including the recruitment of inflammatory cells to sites of infection. Generally speaking, the biological activities of mature IL-1 $\beta$ are targeted towards enhancing the host's inflammatory response.

Given its important role in mediating inflammatory signals, attention has been focused on the role of ASC. In this study, we aimed to elucidate the role of ASC on caspase- 1 expression and IL-1 $\beta$, IL- 6 and TNF- $\alpha$ secretion in the P388D1 macrophagelike cell line in vitro, which may provide new insights into the inflammatory responses of the macrophage.

\section{Materials and methods}

Materials. The TRIzol reagent (Cat. no. 15596-026; Invitrogen Life Technologies, Carlsbad, CA, USA) and RT-PCR kit (Cat. no. DRR024A; Takara Bio, Inc., Shiga, Japan) were obtained from Takara Biotechnology Co., Ltd. (Dalian, China). Lipopolysaccharide (LPS) was derived from Escherichia coli 
serotype O111:B4 (Sigma-Aldrich, St. Louis, MO, USA). ASC antibody (sc-22514-R) and murine ASC-siRNA (sc-37282) were purchased from Santa Cruz Biotechnology, Inc. (Santa Cruz, CA, USA). The plasmid pEGFP-ASC-C2 was a gift from Dr John C. Reed (The Burnham Institute, Scripps Research Institute, La Jolla, CA, USA).

Cell culture. The P388D1 murine macrophage-like cell line was purchased from the Institute of Biochemistry and Cell Biology, Chinese Academy of Sciences (Shanghai, China), and maintained in RPMI-1640 with 10\% fetal bovine serum (FBS), $100 \mathrm{U} / \mathrm{ml}$ penicillin and $100 \mathrm{U} / \mathrm{ml}$ streptomycin at $37^{\circ} \mathrm{C}$ in a humidified atmosphere of $5 \% \mathrm{CO}_{2}$ and $95 \%$ air.

Immunofluorescence assay. The P388D1 cells were seeded on coverslips at a density of $5 \times 10^{5}$ cells/ml and cultured overnight $\left(37^{\circ} \mathrm{C}, 5 \% \mathrm{CO}_{2}, 90 \%\right.$ humidity) prior to treatment. The cells were collected and the coverslips were fixed with freshly prepared $4 \%$ paraformaldehyde for $1 \mathrm{~h}$ at room temperature. The coverslips were then blocked with $5 \%$ bovine serum albumin (BSA) at $37^{\circ} \mathrm{C}$ for $30 \mathrm{~min}$, washed once with phosphate-buffered saline (PBS), stained with ASC-goat polyclonal IgG antibody at $37^{\circ} \mathrm{C}$ for $1 \mathrm{~h}$ and washed three times with PBS, followed by fluorescein isothiocyanate (FITC)-conjugated rabbit anti-goat IgG at $4^{\circ} \mathrm{C}$ for $1 \mathrm{~h}$. As a control, FITC-conjugated rabbit antigoat $\mathrm{IgG}$ was used. Cells were washed with PBS three times and analyzed by fluorescence microscopy using an Olympus BX51 microscope (Tokyo, Japan).

$R T-P C R$ analysis. P388D1 cells were treated with $100 \mathrm{ng} / \mathrm{ml}$ LPS for various lengths of time. The total RNA of the cell was extracted with TRIzol reagent according to the manufacturer's instructions. Human $\beta$-actin was used as an internal control. Briefly, $2 \mu$ g totalRNA was reverse-transcribed intocDNA using a reverse transcription kit (Takara) under the following conditions: $2 \mu 1$ 10X reverse transcriptase buffer, $4 \mu 1 \mathrm{MgCl}_{2}(25 \mathrm{mmol} / \mathrm{l})$, $2 \mu \mathrm{ldNTP}(10 \mathrm{mmol} / \mathrm{l}), 0.5 \mu \mathrm{l}$ RNase inhibitor, $1 \mu \mathrm{l}$ AMV reverse transcriptase enzyme (5 $\mathrm{U} / \mu \mathrm{l})$ and $1 \mu \mathrm{l}$ Random 9-mer, made up with DEPC. The reaction mixture was incubated at $30^{\circ} \mathrm{C}$ for $10 \mathrm{~min}$ and $42^{\circ} \mathrm{C}$ for $30 \mathrm{~min}$, the reverse transcriptase was then inactivated by heating at $99^{\circ} \mathrm{C}$ for $5 \mathrm{~min}$, followed by a final incubation at $5^{\circ} \mathrm{C}$ for $5 \mathrm{~min}$. cDNA $(10 \mu \mathrm{l})$ was used as a template for a $50 \mu \mathrm{l}$ PCR under the following conditions: $5 \mu \mathrm{l}$ 10X buffer, $4 \mu \mathrm{l}$ dNTP, and 0.5 units Taq DNA polymerase. Primers used were: ASC-specific 5'-TAAGCCCATGTCTCTAAGCAC-3' (reverse) and 5'-ATGCCATCCTGGACGCTCTT-3' (forward), caspase-1 5'-CTCCCTCATCTTGTCTTGG-3' (reverse) and 5'-AGACATGGGCTTACAGGA-3' (forward), and $\beta$-actin 5'-CGTCATACTCCTGCTTGCTGATCCACA TCTGC-3' (reverse) and 5'-ATCTGGCACCAAACACCTTCT ACAATGAGCTGCG-3' (forward) for each $1 \mu \mathrm{l}$, made up with water. PCR was performed using a PCR kit (Takara) under the following conditions: initial denaturation at $94^{\circ} \mathrm{C}$ for $2 \mathrm{~min}$, then 35 cycles of $95^{\circ} \mathrm{C}$ for $30 \mathrm{sec}$, annealing at $55^{\circ} \mathrm{C}$ for $45 \mathrm{sec}$ and $72^{\circ} \mathrm{C}$ for $70 \mathrm{sec}$ and a final extension at $72^{\circ} \mathrm{C}$ for $5 \mathrm{~min}$. PCR products were separated by $1.0 \%$ agarose gel electrophoresis and visualized under UV light. $\beta$-actin ( $838 \mathrm{bp}$ ) was used to standardize the amount of cDNA in each sample. To semiquantitate the PCR products, the intensities of the amplified bands were analyzed using AlphaImager software. The band intensities were normalized using the corresponding $\beta$-actin signal, and the correlation ASC $/ \beta$-actin and caspase- $1 / \beta$-actin was determined.

Preparation and expression of the ASC-overexpressing construct $p E G F P-A S C-C 2$. mASC was inserted into pEGFP$\mathrm{C} 2$ with EcoRI and SalI sites. The plasmid pEGFP-ASC-C2 was transfected into P388D1 cells using the Effectene transfection reagent (Cat. no. 301425, Qiagen, Inc.) according to the manufacturer's instructions. In brief, the cells were seeded with $350 \mu 1$ growth medium containing serum and antibiotics in a 24-well plate. DNA $(0.2 \mu \mathrm{g})$ dissolved in TE buffer was diluted to a total volume of $60 \mu \mathrm{l}$. The enhancer was added and mixed by vortexing for $1 \mathrm{sec}$. The mixture was incubated at room temperature for $5 \mathrm{~min}$, spun down for a few seconds to remove drops from the top of the tube, and then $5 \mu 1$ Effectene reagent and $350 \mu 1$ growth medium were added to the tube containing the transfection complexes. After mixing by pipetting, the transfection complexes were immediately added drop-wise to the cells in the 24-well plate. Transfected pEGFP-C2 in P388D1 cells was used as a control.

Transfection of ASC-siRNA into P388D1 cells. The P388D1 cells were seeded overnight in $3.5-\mathrm{cm}$ cell culture dishes, until $40-50 \%$ confluence was achieved at the time of transfection. ASC-siRNA and scrambled siRNA were transfected using Effectene transfection reagent according to the manufacturer's instructions. The effects of the downregulation on ASC were assessed by flow cytometry, RT-PCR and an immunofluorescence assay $30 \mathrm{~h}$ after the transfection. As a control, scrambled siRNA was used, a sequence with no significant homology with target sequence databases.

Cytokine enzyme-linked immunosorbent assay (ELISA). Protein levels of IL-1 $\beta$, IL- 6 and TNF- $\alpha$ in the P388D1 cells were measured using ELISA kits (R\&D Systems, Minneapolis, MN, USA) based on the quantitative immunometric sandwich enzyme immunoassay technique, according to the manufacturer's instructions. Samples were assayed in duplicate and the results were reported as $\mathrm{pg} / \mathrm{ml}$.

Statistical analysis. Data were presented as the mean \pm SD. The Student's t-test was used for statistical analysis. $\mathrm{P}<0.05$ was considered to indicate a statistically significant result.

\section{Results}

ASC expression in the P388D1 macrophage-like cells. To explore the role of ASC in the P388D1 cells, we initially detected the expression of ASC by RT-PCR and immunofluorescence staining assays. RT-PCR demonstrated that the P388D1 cells expressed ASC (Fig. 1A). The immunofluorescence assay showed that ASC was present in the cytoplasm of the $\mathrm{P} 388 \mathrm{D} 1$ cells $(36 \pm 3 \%$ positive, $\mathrm{n}=4)$ (Fig. $1 \mathrm{~B})$, indicating that the P388D1 cell line expressed ASC. Expression of ASC by C57BL/6 mouse thymus gland was used as a control.

ASC overexpression promotes caspase-1 activation, IL-1 $\beta$ and IL-6 secretion, but not TNF- $\alpha$ secretion in P388DI cells. To verify the possibility that ASC overexpression is 
A


Figure 1. ASC expression in macrophage-like P388D1 cells. (A) The results of RT-PCR analysis showed that the P388D1 cells expressed ASC. The thymus of a BALB/c mouse was analyzed as a control (left lane: thymus of a $\mathrm{BALB} / \mathrm{c}$ mouse; right lane: $\mathrm{P} 388 \mathrm{D} 1$ cells). (B) P388D1 cells were incubated with ASC-goat polyclonal IgG at $37^{\circ} \mathrm{C}$ for $1 \mathrm{~h}$ and FITC-conjugated affinipure rabbit anti-goat IgG at $4^{\circ} \mathrm{C}$ for $1 \mathrm{~h}$. Cells were washed with PBS and resuspended in PBS for immunofluorescence assay. As a control, the thymus of a BALB/c mouse was used. The results revealed that ASC was present in the cytoplasms of the P388D1 cells. ASC, apoptosis-associated speck-like protein; FITC, fluorescein isothiocyanate; PBS, phosphate-buffered saline.

effective in macrophage cells, the plasmids pEGFP-ASC-C2 and pEGFP-C2 were transfected into P388D1 cells. Following transfection, the cells expressing high levels of ASC were brightly stained with green fluorescent protein (GFP). Bright green fluorescent signals were observed as speck-like aggregates in the living cells. ASC expression was detected by immunofluorescence assay $30 \mathrm{~h}$ after transfection with pEGFP-ASC-C2 or pEGFP-C2 (Fig. 2A). The ASC protein was overexpressed in the P388D1 cells following transfection with pEGFP-ASC-C2. Transfected plasmid pEGFP-C2 was used as a control.

To determine whether ASC is capable of regulating the production of IL-1 $\beta$, IL- 6 and TNF- $\alpha$ induced by endogenous caspase-1 in response to a physiologically relevant stimulus, ASC-overexpressing P388D1 cells were stimulated with LPS for 6,12 and $24 \mathrm{~h}$ to trigger caspase-1 activation and induce IL-1 $\beta$, IL- 6 and TNF- $\alpha$ secretion. LPS stimulation of the ASC-overexpressing P388D1 cells resulted in an increased caspase-1 mRNA expression (Fig. 2B) and an increased secretion of IL-1 $\beta$, IL- 6 and TNF- $\alpha$ (Fig. 2C-E). The enhancing effect of ASC on the caspase-1-induced secretion of IL-1 $\beta$ and IL-6 was time-dependent and correlated with the amount of ASC protein produced in the transfected cells. Thus, ASC is capable of promoting the production of IL- $1 \beta$ and IL- 6 , but not that of TNF- $\alpha$, which results from the activation of endogenous caspase-1.

ASC expression is silenced by ASC-siRNA in the P388DI macrophage-like cell line. We measured the levels of ASC expression in P388D1 cells transfected with siRNA by RT-PCR and immunofluorescence. ASC-siRNA was able to silence the expression of ASC in the P388D1 cells (Fig. 3A
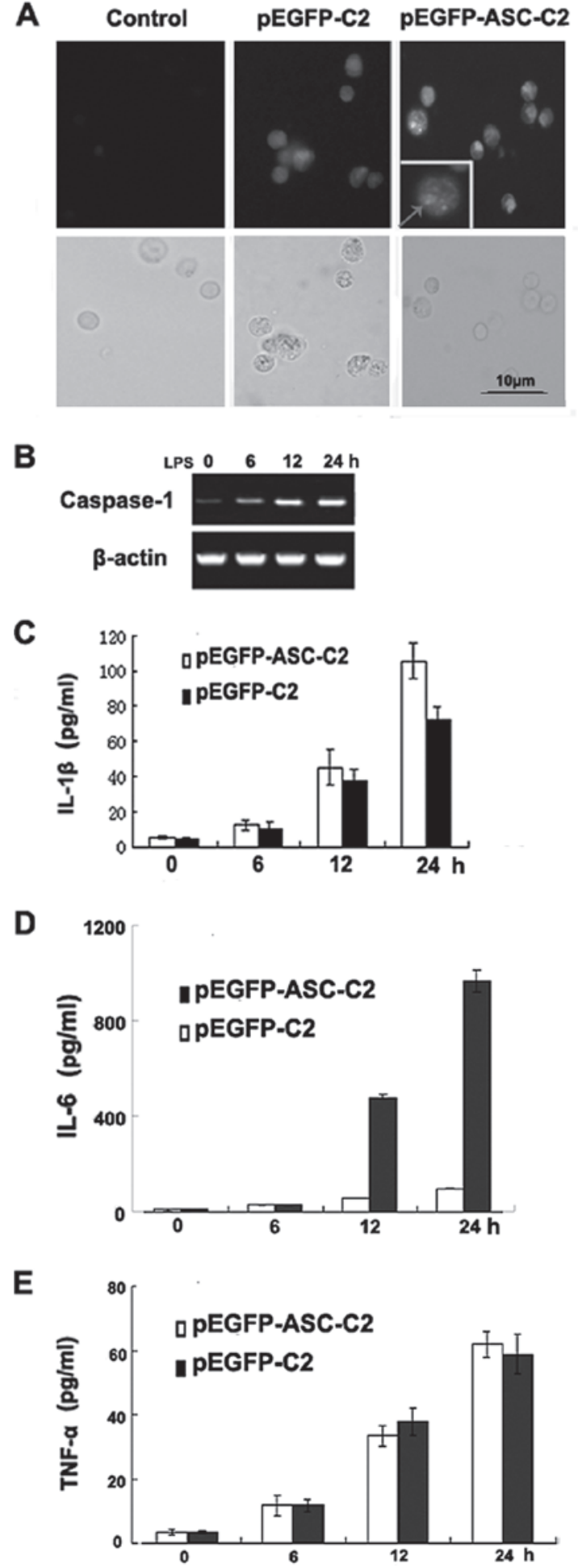

Figure 2. Overexpression of ASC promotes caspase-1 activation and the secretion of IL- $1 \beta$ and IL-6, but not that of TNF- $\alpha$, in the P388D1 macrophage-like cell line. (A) ASC was overexpressed in P388D1 cells transfected with pEGFP-C2. Signals were detected by immunofluorescence microscopy following the staining of ASC with GFP. The right panels show merged images of the fluorescence and transmitted light images (left: control P388D1 cells; middle: P388D1 cells transfected with pEGFP-C2; right: P388D1 cells transfected with pEGFP-ASC-C2). (B) RT-PCR analysis of caspase-1 mRNA. P388D1 cells were transiently transfected with plasmids expressing ASC and 1 day later the cells were stimulated with LPS for 6, 12 and $24 \mathrm{~h}$. (C-E) Promotion of IL-1 $\beta$ and IL-6, but not TNF- $\alpha$, secretion by ASC in a P388D1 cell culture. Supernatants were analyzed for IL-1 $\beta$, IL- 6 and TNF- $\alpha$ at 6,12 and $24 \mathrm{~h}$ post-transfection. Data show the $\mathrm{pg} / \mathrm{ml}$ of IL-1 $\beta$, IL-6 and TNF- $\alpha$ normalized for the cell number (mean $\pm \mathrm{SD} ; \mathrm{n}=3$ ). ASC, apoptosisassociated speck-like protein; IL, interleukin; TNF, tumor necrosis factor; GFP, green fluorescent protein; LPS, lipopolysaccharide. 


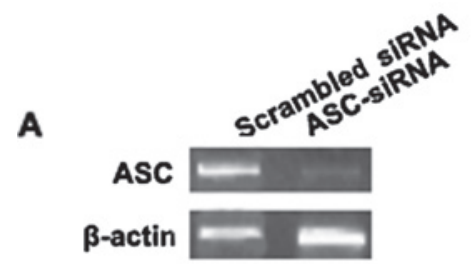

B
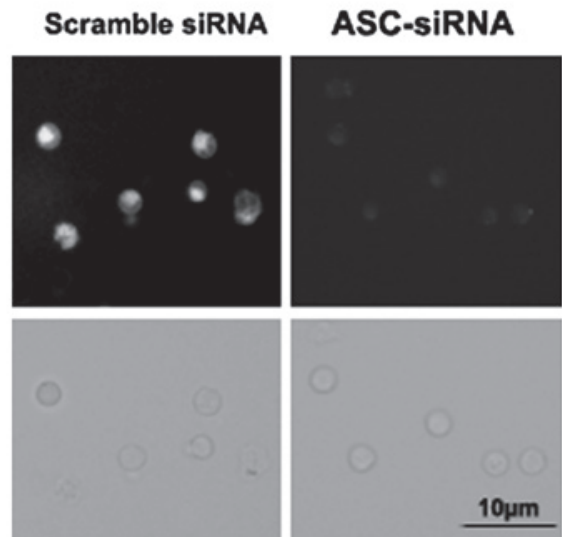

Figure 3. ASC-siRNA silences ASC expression in the P388D1 macrophagelike cells. (A) ASC expression in P388D1 cells was detected by RT-PCR. The expression of ASC in P388D1 cells in the ASC-siRNA group was lower than that in the scrambled siRNA group. (B) Immunofluorescence of ASC-siRNA- and scrambled siRNA-transfected P388D1 cells stained with FITC-labeled secondary Ab revealed that ASC expression can be silenced by ASC-siRNA. ASC, apoptosis-associated speck-like protein; FITC, fluorescein isothiocyanate.

and B). The transfected cells exhibited normal morphology and good viability (Fig. 3B). Silencing of the target gene was observed after $30 \mathrm{~h}$, whereas a similar effect was not observed in the cells transfected with the scrambled siRNA (Fig. 3A and B). The expression of ASC in the P388D1 cells was found to be silenced by ASC-siRNA.

Silencing ASC expression decreases caspase-1 activation and $I L-1 \beta$ and $I L-6$, but not $T N F-\alpha$, secretion in the P388DI macrophage-like cell line. To establish a direct role for ASC-mediated caspase-1 activation and IL-1 $\beta$ secretion, we used siRNAs to inhibit the expression of endogenous ASC in the P388D1 cells and measured caspase- 1 activity and IL-1 $\beta$ secretion. Notably, the inhibition of ASC expression by siRNA decreased the amount of caspase-1 mRNA (Fig. 4A) and reduced the secretion of IL-1 $\beta$ and IL-6, but not that of TNF- $\alpha$ (Fig. 4B-D), in the P388D1 cells. By contrast, the same cells retained their ability to activate caspase- 1 and secrete IL- $1 \beta$ and IL- 6 when incubated with scrambled siRNA. These findings indicate that ASC is required for the secretion of IL-1 $\beta$ and IL- 6 in P388D1 cells.

\section{Discussion}

ASC is one of only two genes in the human genome that contain both PYD and CARD. Such modular protein-protein interaction domains are known to play an important role in many intracellular signal transduction pathways. ASC has been reported to interact with the CARD of pro-caspase-1 and induce aggregation of the inflammasome, thereby regulating the activation of caspase- 1 and the secretion of IL-1 $\beta(19,20)$.
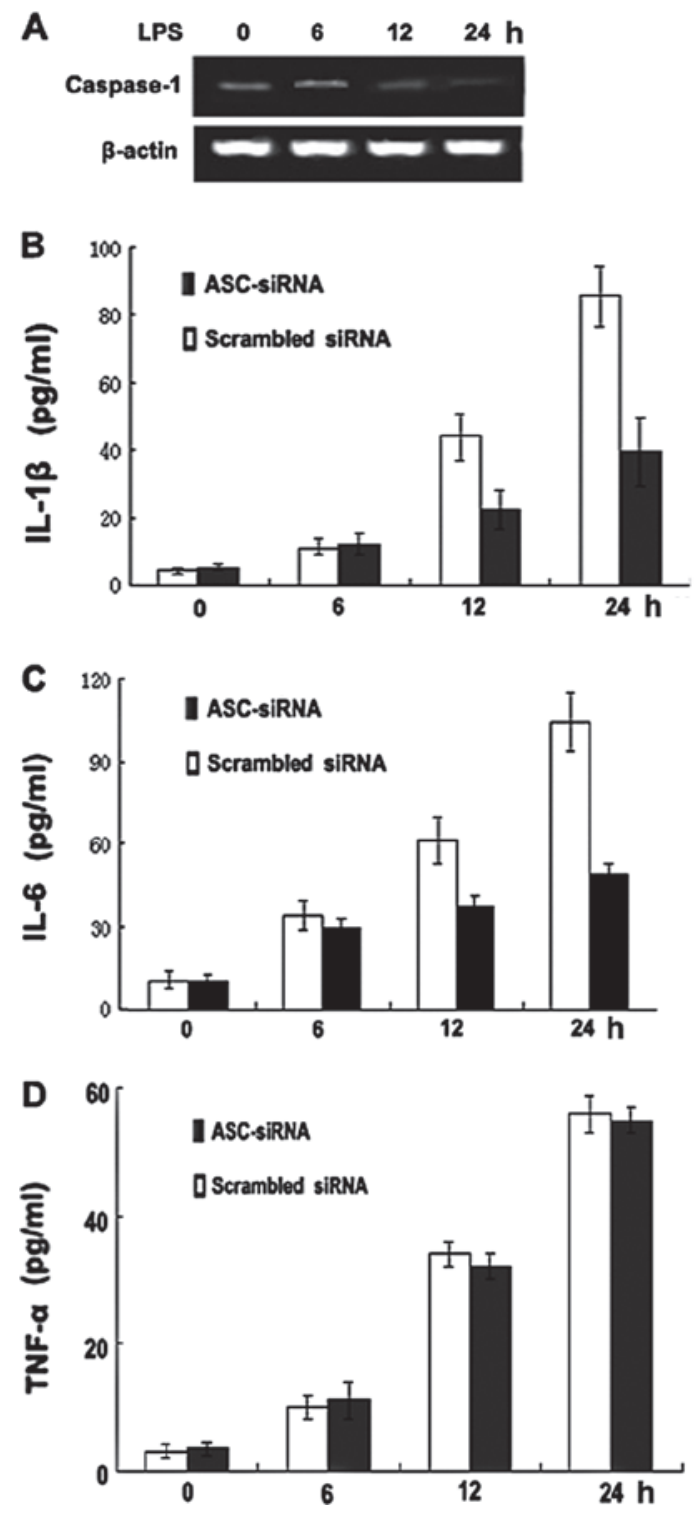

Figure 4. ASC-siRNA decreases caspase-1 activation and IL-1 $\beta$ and IL-6, but not TNF- $\alpha$, secretion in the P388D1 macrophage-like cell line. (A) RT-PCR analysis of caspase-1 mRNA. P388D1 cells were transiently transfected with ASC-siRNA and 1 day later were stimulated with LPS for 6, 12 and $24 \mathrm{~h}$. (B-D) Decrease of IL-1 $\beta$ and IL-6, but not TNF- $\alpha$, secretion by ASC-siRNA in a P388D1 cell culture. Supernatants were analyzed for IL-1 $\beta$, IL-6 and TNF- $\alpha$ at 6,12 and $24 \mathrm{~h}$ post-transfection. Data show the $\mathrm{pg} / \mathrm{ml}$ of IL-1 $\beta$, IL- 6 and TNF- $\alpha$ normalized for the cell number (mean $\pm \mathrm{SD} ; \mathrm{n}=3$ ). ASC, apoptosisassociated speck-like protein; IL, interleukin; TNF, tumor necrosis factor; LPS, lipopolysaccharide.

In this study, we have extended existing data regarding the role of ASC in caspase-1 activation. We investigated the relationship between ASC and caspase-1 in P388D1 cells, and our data confirm that ASC overexpression induced by pEGFP-ASC-C2 transfection significantly increased caspase-1 expression levels and the secretion of IL-1 $\beta$ and IL-6, but not TNF- $\alpha$ secretion. We extended this observation to the opposite situation, in which suppression of ASC expression, using siRNA, significantly reduced caspase-1 expression and IL-1 $\beta$ and IL- 6 secretion.

Caspase-1 exists in two activation states, unprocessed and fully processed, depending on the composition of the inflammasome. Inflammasome formation is coordinated by members 
of the NLR protein family or the PYHIN protein family that function as specific sensors for a variety of pathogens and other inflammatory stimuli (21). ASC appears to function as a vital adaptor for the recruitment of caspase-1 to PYRIN-containing receptors. This function indicates that regulation of the availability of ASC is a potential mechanism for the modulation of caspase-1-mediated cytokine processing. Other studies have demonstrated that ASC is crucial for the induction of caspase-1 processing, which appears to be essential for efficient cytokine maturation (22). When activated, the pro-caspase-1 zymogen promotes macrophage cell death, but requires ASC to be processed to its 10 - and $20-\mathrm{kDa}$ subunits to promote the maturation of cytokines, including IL-1 $\beta$ and IL-18.

IL-1 $\beta$ increases the activity of nuclear factor $\kappa \mathrm{B}(\mathrm{NF}-\kappa \mathrm{B})$, a transcription factor that regulates numerous pro-inflammatory genes. IL- $1 \beta$ activates NF- $\kappa B$ through a cascade that involves activating NF- $\mathrm{kB}$-inducing kinase, which then phosphorylates and activates the inhibitor of NF- $\mathrm{KB}(\mathrm{I} \kappa \mathrm{B})$ kinase.

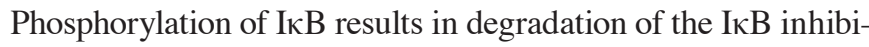
tory subunit, allowing NF- $\kappa B$ to translocate to the nucleus, where it acts as a transcription factor and regulates its target genes (23). It has been demonstrated that the transcription of several inflammatory genes, including IL- 6 and TNF- $\alpha$, is regulated by NF- $\mathrm{BB}(24,25)$. Consistent with these findings, we found that the upregulation of ASC induces not only the expression of caspase-1, but also the secretion of IL-1 $\beta$ and IL-6. Conversely, the downregulation of ASC inhibits the expression of caspase-1 and the secretion of IL-1 $\beta$ and IL- 6 . Notably, the secretion of TNF- $\alpha$ was not significantly upregulated or downregulated by the changes in the expression of ASC. One likely reason for the failure of ASC to change the secretion of TNF- $\alpha$ is that this process also needs the involvement of additional transcription factors, including STAT3 (26), which may be inadequate.

In conclusion, accumulating evidence suggests that ASC is important in the regulation of inflammatory responses by macrophages, and acts primarily by affecting the secretion of cytokines, such as IL-1 $\beta$ and IL-6. Our results strongly suggest that ASC is involved in this process.

\section{Acknowledgements}

This study was supported by a grant from NSFC (90709005 and 30973851 and 81173452).

\section{References}

1. Gabay C: Interleukin-6 and chronic inflammation. Arthritis Res Ther 8: S3, 2006.

2. Abdelaziz DH, Gavrilin MA, Akhter A, Caution K, Kotrange S, Khweek AA, Abdulrahman BA, Grandhi J, Hassan ZA, Marsh C, et al: Apoptosis-associated speck-like protein (ASC) controls Legionella pneumophila infection in human monocytes. J Biol Chem 286: 3203-3208, 2011.

3. Masumoto J, Taniguchi S, Ayukawa K, Sarvotham H, Kishino T, Niikawa N, Hidaka E, Katsuyama T, Higuchi T and Sagara J: ASC, a novel 22-kDa protein, aggregates during apoptosis of human promyelocytic leukemia HL-60 cells. J Biol Chem 274: 33835-33838, 1999.

4. Petrilli V, Papin S and Tschopp J: The inflammasome. Curr Biol 15: R581, 2005

5. Fernandes-Alnemri T, Wu J, Yu JW, Datta P, Miller B, Jankowski W, Rosenberg S, Zhang J and Alnemri ES: The pyroptosome: a supramolecular assembly of ASC dimers mediating inflammatory cell death via caspase-1 activation. Cell Death Differ 14: 1590-1604, 2007.
6. Srinivasula SM, Poyet JL, Razmara M, Datta P, Zhang Z and Alnemri ES: The PYRIN-CARD protein ASC is an activating adaptor for Caspase-1. J Biol Chem 277: 21119-21122, 2002.

7. Yu HB and Finlay BB: The Caspase-1 inflammasome: a pilot of innate immune responses. Cell Host Microbe 4: 198-208, 2008.

8. Akhter A, Gavrilin MA, Frantz L, Washington S, Ditty C, Limoli D, Day C, Sarkar A, Newland C, Butchar J, et al: Caspase-7 activation by the Nlrc4/Ipaf inflammasome restricts Legionella pneumophila infection. PLoS Pathog 5: e1000361, 2009.

9. Lamkanfi M, Kanneganti TD, Van Damme P, Vanden Berghe T, Vanoverberghe I, Vandekerckhove J, Vandenabeele P, Gevaert K and Núñez G: Targeted peptidecentric proteomics reveals Caspase-7 as a substrate of the Caspase-1 inflammasomes. Mol Cell Proteomics 7: 2350-2363, 2008.

10. Lamkanfi M, Moreira LO, Makena P, Spierings DC, Boyd K, Murray PJ, Green DR and Kanneganti TD: Caspase-7 deficiency protects from endotoxin-induced lymphocyte apoptosis and improves survival. Blood 113: 2742-2745, 2009.

11. Franchi L, Eigenbrod T, Planillo RM and Nuñez G: The inflammasome: a caspase-1 activation platform regulating immune responses and disease pathogenesis. Nat Immunol 10: 241-247, 2009.

12. Martinon F and Tschopp J: Inflammatory caspases and inflammasomes: master switches of inflammation. Cell Death Differ 14: 10-22, 2007.

13. Nicholson DW: Caspase structure, proteolytic substrates, and function during apoptotic cell death. Cell Death Differ 6: 1028-1042, 1999.

14. Cerretti DP, Kozlosky CJ, Mosley B, et al: Molecular cloning of the interleukin-1 beta converting enzyme. Science 256: 97-100, 1992.

15. Thornberry NA, Bull HG, Calaycay JR, et al: A novel heterodimeric cysteine protease is required for interleukin-1 beta processing in monocytes. Nature 356: 768-774, 1992.

16. Martinon F and Tschopp J: Inflammatory caspases: linking an intracellular innate immune system to autoinflammatory diseases. Cell 117: 561-574, 2004.

17. Netea MG, Nold-Petry CA, Nold MF, et al: Differential requirement for the activation of the inflammasome for processing and release of IL-1 1 beta\} in monocytes and macrophages. Blood 113: 2324-2335, 2009.

18. Kuijk LM, Beekman JM, Koster J, Waterham HR, Frenkel J and Coffer PJ: HMG-CoA reductase inhibition induces IL-1beta release through $\mathrm{Rac1} / \mathrm{PI} 3 \mathrm{~K} / \mathrm{PKB}$-dependent caspase-1 activation. Blood 112: 3563-3573, 2008.

19. Srinivasula SM, Poyet JL, Razmara M, Datta P, Zhang Z and Alnemri ES: The PYRIN-CARD protein ASC is an activating adaptor for caspase-1. J Biol Chem 277: 21119-21122, 2002.

20. Stehlik C, Lee SH, Dorfleutner A, Stassinopoulos A, Sagara J and Reed JC: Apoptosis-associated Speck-like protein containing a caspase recruitment domain is a regulator of procaspase-1 activation. J Immunol 171: 6154-6163, 2003.

21. Brodsky IE and Monack D: NLR-mediated control of inflammasome assembly in the host response against bacterial pathogens. Semin Immunol 21: 199-207, 2009.

22. Broz P, Moltke J, Jones JW, Vance R and Monack DM: Differential requirement for Caspase-1 autoproteolysis in pathogen-induced cell death and cytokine processing. Cell Host Microbe 8: 471-483, 2010.

23. Mengshol JA, Vincenti MP, Coon CI, Barchowsky A and Brinckerhoff CE: Interleukin-1 induction of collagenase 3 (matrix metalloproteinase 13) gene expression in chondrocytes requires $\mathrm{p} 38$, c-jun $\mathrm{N}$-terminal kinase, and nuclear factor $\kappa \mathrm{B}$ : differential regulation of collagenase 1 and collagenase 3 . Arthritis Rheum 43: 801-811, 2000.

24. Hagemann T, Biswas SK, Lawrence T, Sica A and Lewis CE: Regulation of macrophage function in tumors: the multifaceted role of NF-кB. Blood 113: 3139-3146, 2009.

25. Karin $M$ and Greten FR: NF- $\kappa$ B: linking inflammation and immunity to cancer development and progression. Nat Rev Immunol 5: 749-759, 2005.

26. Biswas $\mathrm{S}$ and Lewis $\mathrm{CE}$ : NF- $\kappa \mathrm{B}$ as a central regulator of macrophage function in tumors mechanism and repertoire of ASC-mediated gene expression. JLB 88: 877-884, 2010. 